\title{
Assessing asphalt mixture moisture susceptibility through intrinsic adhesion, bitumen stripping and mechanical damage
}

\author{
James Grenfell ${ }^{1 *}$, Naveed Ahmad ${ }^{2}$, Yawen Liu ${ }^{1}$, Alex Apeagyei ${ }^{1}$, David Large ${ }^{3}$ and \\ Gordon Airey ${ }^{1}$ \\ ${ }^{1}$ Nottingham Transportation Engineering Centre, University of Nottingham, \\ Nottingham NG7 2RD, United Kingdom. \\ Telephone: +44 115 9513905, Fax: +44 1159513909 \\ Email: james.grenfell@ nottingham.ac.uk \\ ${ }^{2}$ Department of Civil Engineering, University of Engineering and Technology, \\ Taxila, 47050, Pakistan \\ ${ }^{3}$ Department of Chemical and Environmental Engineering, University of Nottingham, \\ Nottingham NG7 2RD, United Kingdom.
}

Word Count: $5045+1$ Table +9 Figures $=7,545$

\begin{abstract}
Durability is one of the most important properties of an asphalt mixture. A key factor affecting the durability of asphalt pavements is moisture damage. Moisture damage is generally considered to be the result of two main mechanisms; the loss of adhesion between bitumen and aggregate and the loss of cohesion within the mixture. Conventional test methods for evaluating moisture damage include tests conducted on loose bitumen-coated aggregates and those conducted on compacted asphalt mixtures. The former test methods are simpler and less expensive to conduct but are qualitative/subjective in nature and do not consider cohesive failure while the latter, though more quantitative, are based on bulky mechanical test set-ups and therefore require expensive equipment. Both test methods are, however, empirical in nature thus requiring extensive experience to interpret/use their results. The rolling bottle test (EN 12697-11) for loose aggregate mixtures and the Saturation Ageing Tensile Stiffness (SATS) test (EN 12697-45) for compacted asphalt mixtures are two such methods, which experience suggests, could clearly discriminate between 'good' and
\end{abstract}


'poor' performing mixtures in the laboratory. A more fundamental approach based on surface energy (SE) measurements offers promise to better understand moisture damage. This paper looks at results from the rolling bottle and the SATS tests in an attempt to better understand the underlying processes and mechanisms of moisture damage with the help of surface energy measurements on the constituent bitumen and aggregates. For this work, a set of bitumens and typical acidic and basic aggregate types were selected. Combinations of these materials were assessed using both the rolling bottle and SATS tests. The surface energy properties of the binders were measured using a Dynamic Contact Angle Analyser and those of the aggregates using a Dynamic Vapour Sorption device. From these surface energy measurements it was possible to predict the relative performance of both the simple rolling bottle test and the more complicated SATS test. Mineralogical composition of the aggregates determined using a Mineral Liberation Analyser was used to explain the differences in performance of the mixtures considered.

Keywords: Bitumen; Asphalt mixtures; Surface energy; Moisture damage; SATS; Rolling Bottle Test, Adhesion, Mineralogical composition.

\section{Introduction}

The majority of the roads throughout the world are constructed by using asphalt mixtures. However, like any other man-made structure, asphalt pavements deteriorate with the passage of time. Moisture damage is considered to be one of the major causes of distress in asphalt pavements with almost 2.5 billion pounds being spent annually by local authorities in England and Wales for road maintenance and rehabilitation works (ALARM, 2006). Although not all damage is caused directly by moisture, its presence increases the extent and severity of already existing distresses like cracking, potholes and rutting (Miller and Bellinger, 2003). The presence of moisture results in the degradation of the mechanical properties of the asphalt mixture, i.e. loss of stiffness and mechanical strength, which ultimately leads to the failure of the road structure. Moisture damage thus has a great economic impact as it causes premature pavement failure and hence results in increased rehabilitation work and maintenance costs. 
Bitumen and aggregates are considered as the main constituents of an asphalt mixture and their physical and chemical properties have a direct influence on the performance of the mixture. A lack of compatibility between bitumen and aggregate is one of the main causes of moisture damage in an asphalt mixture. Moisture damage is normally related to the loss of adhesion between bitumen and aggregate and/or loss of cohesion within the bitumen (or more realistically the bitumen-filler mastic) in the presence of water (Terrel and Al-Swailmi, 1994). Replacement of bitumen film from the aggregate surface by water is termed 'stripping' (Kandhal et al., 1994), with this phenomenon depending largely on the chemical composition of the bitumen and aggregates, and their affinity towards each other (Emery and Seddik, 1997). The bitumen film is removed from the surface of aggregates in the presence of water because of weak adhesive bond between the two (bitumen and aggregate) materials. Hence the individual properties of the material, along with the properties of the resulting asphalt mixture, largely affect the structural performance of the road pavement.

It is important to be able to identify materials and asphalt mixtures that are prone to moisture damage. A number of laboratory tests have been developed over the years to determine the moisture susceptibility of asphalt mixtures but the majority do not show good correlation between the results obtained in the laboratory and the field performance of the mixtures (Solaimanian et al., 2003; Birgisson et al. 2005). In most of these tests, the moisture sensitivity/damage is simply related to the mechanical properties of the bulk asphalt mixture with the physical and chemical properties of the individual materials (bitumen and aggregate) not being addressed. These physicochemical properties are directly related to the adhesion characteristics of the two materials and are responsible for adhesion or debonding between the materials (MS24, 2007). Surface energy (or more correctly surface free energy) properties of the materials can be used to assess these adhesion characteristics (Bhasin, 2006). Surface free energy (SFE) can therefore be considered to truly represent the physico-chemical surface characteristics of bitumen and aggregates and has been successfully used as a tool for selection of moisture resistant materials (Cheng, 2002). The physico-chemical characteristics of bitumen and aggregates, which can be assessed using surface energy principles, are believed to be a key factor responsible for the adhesion between the two materials. 
While the surface energy properties of the bitumen and aggregates can be successfully used to assess the cohesive and adhesive bond strengths of the two materials, the effect of moisture/water on the bond strength of a bitumen-aggregate system can also be assessed by using SFE and various thermodynamic calculations (Bhasin et al., 2006; Cheng et al., 2002a, and Cheng et al., 2002b). The measurement of these fundamental material properties related to adhesion and cohesion can be used to explain the cause of poor and good moisture performance. However, because of the complex nature of asphalt material and the fact that the surface energy properties of the material (bitumen and aggregate) can be considerably different to its bulk chemistry, the use of SFE and related theories to address moisture damage is not straight forward (Kim, 2009).

This paper presents a combination of surface energy testing techniques with mechanical moisture sensitivity assessment techniques for identification of compatible bitumen-aggregate combinations. A complete characterisation is possible once results from SFE measurements and calculations are compared with those of standard mechanical tests. Tests like the rolling bottle test (RBT) and the saturated ageing tensile stiffness (SATS) test are considered good for the comparative analysis of the moisture susceptibility of asphalt mixtures (Airey and Choi, 2006). The RBT and SATS techniques have therefore been included to provide a comparison to the surface energy results for various bitumen-aggregate combinations.

\section{Materials}

\subsection{Constitutive materials}

Four aggregates commonly used in UK asphalt mixtures were chosen for the study. The aggregates (two limestones and two granites) were selected based on their difference in mineralogy and the fact that they exhibit different moisture damage performance (Airey et al., 2007). The mineralogy of the different aggregates was studied using a Mineral Liberation Analyser (MLA) in order to understand their morphology and to help with the overall analysis of results. 
MLA comprises a procedure used to identify the mineral phases present in aggregates by combining a large specimen chamber automated Scanning Electron Microscope (SEM) and multiple Energy Dispersive X-ray detectors with automated quantitative mineralogy software. The software controls the SEM hardware to quantitatively analyse mineral and material samples. Automated stage control and image acquisition allows for rapid and systematic Back Scattered Electron (BSE) imaging and subsequent X-ray analysis of thousands of mineral grains and particles. Automatic recalibration ensures consistent results. An FEI Quanta 600 SEM with MLA capability was used for the mineral phase determination (see Figure 1). Aggregate samples were prepared by casting aggregates in resin, followed by polishing of the surface. The samples were then carbon coated to make them electron conductive and scanned in BSE mode with Electron Dispersive X-ray analysis (EDX) being carried out in an array of spots across the particles. The resultant spectra were then used to determine mineral phases at specific points in the microstructure which allowed mineralogical maps to be generated for each of the aggregate types.

The MLA results for all the aggregates used in this study (Limestone A, B and Granite A, B) are presented in Table 1. The results show that the aggregates have significantly different mineralogical make-up with Limestone A being made up of predominantly (about 97\%) calcite. Granite A, on the other hand, is made up of a number of different mineral phases with the predominant phase being quartz, but with significant quantities of albite and $\mathrm{K}_{-}$feldspar. It is believed that the large proportion of the quartz phase has the potential to lead to deleterious moisture properties, due to the poor adhesion between quartz and bitumen. However, there is also evidence that a high feldspar content can be responsible for interfacial failure between bitumen and aggregate surfaces (Horgnies et al., 2011). A typical MLA result shown as an iumage obtained from Granite A is shown in Figure 2.

In general, the limestone aggregates, being basic, are believed to perform better in practice as well as in moisture sensitivity tests, while the granite aggregates have been found to perform poorly in previous moisture sensitivity work (Grenfell et al., 2012). 


\subsection{Asphalt mixture}

Twelve combinations of the four aggregates (two limestones and two granites) and three bitumens (15, 50 and 100 penetration grades) were included in the study. A standard continuously graded 0/32 $\mathrm{mm}(28 \mathrm{~mm})$ dense bitumen macadam (DBM) base material was used with the four aggregate types. The grading curves for Limestone A and Granite A, based on the mixture design for the $0 / 32 \mathrm{~mm}$ DBM, are shown in Figure 3. All four asphalt mixtures (two limestones and two granites) were within the specified grading envelope.

A target binder content of $4 \%$ by total mixture mass was selected for all the asphalt mixtures and roller compacted slabs (305 mm x $305 \mathrm{~mm}$ x $100 \mathrm{~mm}$ ) were manufactured and finally cored and trimmed to produce $100 \mathrm{~mm}$ diameter by $60 \mathrm{~mm}$ high specimens with a target air voids content of between 8 and 10\% (typical of field cores). Only cores that achieved this target were selected for the SATS test.

\section{Testing methodology}

\subsection{Surface Free Energy}

The surface free energy of a material is defined as the energy needed to create a new unit surface area of the material in a vacuum condition. The surface energies of bitumen and aggregate or a bitumen-aggregate system (asphalt mixture) are mainly comprised of an apolar (nonpolar) component and an acid-base component (Fowkes, 1962; Good and van Oss, 1991 and Good, 1992). Equation 1 is used to describe the total surface energy and its components:

$$
\gamma=\gamma^{L W}+\gamma^{A B}
$$

Where: $\gamma=$ surface energy of bitumen or aggregate $\left(\mathrm{mJ} / \mathrm{m}^{2}\right)$;

$\gamma^{\mathrm{LW}}=$ Lifshitz-van der Waals component of the surface energy $\left(\mathrm{mJ} / \mathrm{m}^{2}\right)$; and $\gamma^{\mathrm{AB}}=$ acid-base component of the surface energy $\left(\mathrm{mJ} / \mathrm{m}^{2}\right)$. 
The Lifshitz-van der Waals force contains at least three components: London dispersion forces, Debye induction forces, and Keesom orientation forces (Maugis, 1999). The acid-base interaction includes all interactions of electron donor (proton acceptor) - electron acceptor (proton donor) type bonds including hydrogen bonding. To quantitatively predict and treat the acid-base interaction, Good and van Oss (1991) postulated a resolution of the acid-base term, $\gamma^{\mathrm{AB}}$ into a Lewis acidic surface parameter and a Lewis basic surface parameter. The relationship among the $\gamma^{\mathrm{AB}}$ and its components is shown in equation 2 :

$$
\gamma^{A B}=2 \sqrt{\gamma^{+} \gamma^{-}}
$$

Where: $\gamma^{+}=$Lewis acid component of surface interaction, and $\gamma^{-}=$Lewis base component of surface interaction.

\subsection{Dynamic Contact Angle (DCA) Tests}

Surface energy components of the bitumen were determined indirectly using contact angle measurements. A Cahn Model dynamic contact angle analyser (Figure 4) was used to measure the contact angles of a set of three carefully selected probe liquids on bitumen coated glass slides under dynamic conditions. The probe liquids used included water, glycerol and diiodomethane. All the tests were conducted at room temperature $\left(23^{\circ} \mathrm{C} \pm 2^{\circ} \mathrm{C}\right)$ and $50 \% \pm 5 \%$ relative humidity. During the test, a clean $40 \mathrm{~mm}$ x $24 \mathrm{~mm}$ x $0.45 \mathrm{~mm}$ No. 15 microscope glass slide was coated with bitumen and hung from the balance of the DCA equipment with the help of a crocodile clip (Figure 4). A beaker containing a probe liquid was placed on a movable stage positioned under the glass slide. The bottom edge of the slide was kept parallel with the surface of the probe liquid. The bitumen-coated glass slide was then immersed up to a maximum depth of $5 \mathrm{~mm}$ (advancing) and then withdrawn (receding) from the liquid by moving the stage up and down, respectively, at a constant speed of 40 microns/sec while continuously recording the change in mass of the bitumen-coated slide with depth of immersion. The measured mass-depth relationships were used to estimate the force acting on the bitumen-slide while being immersed or removed from 
probe liquid and used subsequently to determine the contact angle between bitumen and probe liquid.

The contact angle $(\theta)$ values are obtained by considering the equilibrium forces acting on the bitumen-coated slide while advancing and receding from the probe liquid using Eq. 3 (Bhasin, 2006):

$\cos \theta=\frac{\Delta F+V_{i m}\left(\rho_{L}-\rho_{\text {air }} g\right)}{P_{t} \gamma_{L}}$

Where: $P_{t}=$ perimeter of the bitumen coated plate

$\gamma_{L}=$ total surface energy of the probe liquid

$\Delta F=$ difference between weight of plate in air and partially submerged in probe liquid

$V_{i m}=$ volume of solid immersed in the liquid

$\rho_{L}=$ density of the liquid

$\rho_{\text {air }}=$ air density

$g=$ gravitational force

To obtain surface energy values for the bitumen, contact angle values for at least three probe liquids are measured and applied to the Young-Dupré equation (Eq. 4) for the work of adhesion $\left(\mathrm{W}_{\mathrm{SL}}\right)$ between the two materials. Three equations are thus produced using the known surface energy components of the three probe liquids (Table 1) for the determination of the three surface energy components $\left(\gamma^{L W}, \gamma^{+}, \gamma^{-}\right)$of the bitumen.

$\mathrm{W}_{\mathrm{SL}}=\gamma_{L}(1+\cos \theta)=2 \sqrt{\gamma_{S}^{L W} \gamma_{L}^{L W}}+2 \sqrt{\gamma_{S}^{-} \gamma_{L}^{+}}+2 \sqrt{\gamma_{S}^{+} \gamma_{L}^{-}}$

Where subscripts $\mathrm{L}$ and $\mathrm{S}$ represents liquid and solid respectively, and $\theta$ is the contact angle. 


\subsection{Dynamic Vapour Sorption (DVS) Test}

It is difficult to use the contact angle technique on high surface energy materials like aggregates (SFE values generally $>60 \mathrm{~mJ} / \mathrm{m}^{2}$ ) as probe liquids readily spread on high energy surfaces and it is difficult to obtain accurate contact angles. Therefore, for this study a dynamic vapour sorption system (DVS Advantage 2, Surface Measurement Systems, Middlesex, UK) shown in Figure 5 was used to determine sorption isotherms for the various aggregates and probe vapour combinations and the results used to determine the SFE components of the aggregate. The desired partial vapour pressures were varied from 0 to $95 \%$ with $5-10 \%$ increments (14 steps).

Prior to testing, the aggregates to be tested were first washed with deionised water and then dried in an oven to constant mass (up to 16 hours). Aggregate fraction passing $5 \mathrm{~mm}$ and retained on $2.36 \mathrm{~mm}$ was used. The upper limit on aggregate size is dictated by the material holding capacity of the sample chamber. The cleaned oven-dried aggregate samples (less than $10 \mathrm{~g}$ ) were again pre-heated in the DVS sample chamber at a temperature of $110^{\circ} \mathrm{C}$ for up to five hour to completely dry the samples before the sorption test.

To perform the sorption test, carefully selected probe vapours (octane, ethyl acetate, and chloroform) with known SFE components were passed through the aggregate sample, under controlled temperature and partial vapour pressure conditions, with the aid of an inert carrier gas (nitrogen). The probes that were chosen for the aggregate testing had relatively low surface tension values as compared to the ones that are used for testing the bitumen to aid the ability to achieve a uniform adsorption/monolayer of the probe on the aggregate surface. Due to the surface characteristics of the aggregate, vapour probes get adsorbed on their surfaces which results in an increase in the mass of the aggregate sample that is then measured using a sensitive balance.

During the test, the aggregate material was exposed to different concentrations/vapour pressures of the probe liquids (shown in Figure 6) and the increase in mass of the aggregates because of adsorption of the probe vapours on the aggregate surface was measured. All the tests were performed at a temperature of $25^{\circ} \mathrm{C}$. The change in mass of an aggregate sample was plotted against the increasing partial vapour pressure 
values to generate sorption isotherms which were used to estimate specific surface area and spreading equilibrium pressures of the aggregates.

\subsubsection{Specific surface area}

A typical obtained adsorption isotherm is shown in Figure 7 for Limestone A aggregate with octane probe vapour for partial vapour pressures (concentrations) ranging from 0 to $95 \%$. Similar isotherms were obtained for the other aggregates. From Figure 7, it can be seen that the plot of adsorbed mass versus partial vapour pressures for Limestone A shows characteristics typical of Type II isotherms (Erbil, 2006). This suggests that the BET model can be used to fit the sorption isotherms (up to $35 \%$ partial vapour pressure) using the Langmuir approach (Eq. 5) as shown in Figure 8 , where a plot of $\mathrm{P} /\left(\mathrm{P}_{0}-\mathrm{P}\right) n$ against $\mathrm{P} / \mathrm{P}_{0}$ gives a straight line from which the BET constant (c) and the specific amount of vapour adsorbed on the surface of aggregate $\left(\mathrm{n}_{\mathrm{m}}\right)$, can be obtained. The results were used to estimate the specific surface area of the aggregates using Eq. 6 (Shaw, 1991 and Sing, 1969).

$$
\frac{P}{n\left(P_{0}-P\right)}=\left(\frac{c-1}{n_{m} c}\right) \frac{P}{P_{0}}+\frac{1}{n_{m} c}
$$

Where: $P=$ partial vapour pressure, $\mathrm{Pa}$

$P_{0}=$ saturated vapour pressure of solvent, $\mathrm{Pa}$

$n=$ specific amount adsorbed on the surface of the absorbent, mg; and

$c=$ BET constant (parameter theoretically related to the net molar enthalpy of the adsorption)

$$
S S A=\left(\frac{n_{m} N_{o}}{M}\right) \alpha
$$

Where: $S S A=$ specific surface area of solid, $\mathrm{m}^{2}$

$n_{m}=$ monolayer specific amount of vapour adsorbed on the aggregate surface, $\mathrm{mg}$

$N_{0}=$ Avogadro's number, $6.022 \times 10^{23} \mathrm{~mol}^{-1}$

$M=$ molecular weight of the vapour, $\mathrm{g} / \mathrm{mol}$ 
$\alpha=$ projected or cross-sectional area of the vapour single molecule, $\mathrm{m}^{2}$

\subsubsection{Spreading Pressure}

In addition to estimating the specific surface as previously described, the sorption isotherms were also used to calculate the spreading pressure which is required to determine surface energy components of the aggregates. Adsorption of vapour molecules on the aggregate surface reduces its SFE, so spreading pressure, as a result of adsorption of the vapour molecules, can be expressed as:

$$
\pi_{e}=\gamma_{S}-\gamma_{S V}
$$

Where: $\pi_{e}=$ spreading pressure at maximum saturated vapour pressure or equilibrium spreading pressure, $\mathrm{mJ} / \mathrm{m}^{2}$

$\gamma_{S}=$ aggregate surface energy in vacuum

$\gamma_{S V}=$ aggregate surface energy after exposure to vapour

Spreading pressure at maximum saturation vapour pressure, $\pi_{e}$ for each solvent, is calculated by using the following Gibbs free energy model (Eq. 8):

$$
\pi_{e}=\frac{R T}{A} \int_{0}^{P o} \frac{n}{P} d P
$$

Where: $R=$ universal gas constant, $83.14 \mathrm{~cm}^{3} \mathrm{bar} / \mathrm{mol} . \mathrm{K}$

$T=$ absolute temperature, $\mathrm{K}$

By introducing spreading pressure, $\pi_{e}$, in the Young-Dupre relation (Eq. 4), the following relationship is obtained:

$W_{S L}=\pi_{e}+\gamma_{L V}(1+\cos \theta)$ 
The contact angle value for high energy solids such as aggregates is zero, therefore, Eq. 9 can be re-written as:

$$
W_{S L}=\pi_{e}+2 \gamma_{L V}
$$

By substituting the above relation in Eq. 4, the following equation is obtained:

$$
2 \gamma_{L}+\pi_{e}=2 \sqrt{\gamma_{S}^{L W} \gamma_{L}^{L W}}+2 \sqrt{\gamma_{S}^{+} \gamma_{L}^{-}}+2 \sqrt{\gamma_{S}^{-} \gamma_{L}^{+}}
$$

From Eq. 11, if the spreading pressures from three different probe vapours are measured, then the three surface energy components of the aggregates $\left(\gamma_{S}^{L W}, \gamma_{S}^{+}, \gamma_{S}^{-}\right)$ can be determined by solving three simultaneous equations.

The surface energy properties of the bitumen and the aggregates on their own have very little significance. However, when combined thermodynamically, they are helpful for estimating the interfacial work of adhesion between the two materials, with or without the presence of moisture.

\subsection{Dry and wet work of adhesion}

The main objective for measuring surface energy of bitumen and aggregates is to be able to estimate the moisture sensitivity of asphalt mixtures using the principles of thermodynamics and physical adhesion. This objective was accomplished by using the surface energy properties of the aggregate and bitumen to calculate their interfacial work of adhesion (dry bond strength) and the reduction in free energy of the system (work of debonding) when water displaces bitumen from the aggregate-bitumen interface (Eqs 12 and 13). For an asphalt mixture to be durable and less sensitive to moisture, it is desirable that the work of adhesion between the bitumen and the aggregate be as high as possible.

In addition to the two parameters: dry bond strength and work of debonding, a third parameter, the cohesion of bitumen, can be calculated from the surface energy properties of bitumen. These three bond energy parameters (bitumen cohesion, dry 
bond strength, and work of debonding) can then be used to assess the moisture sensitivity of an asphalt mixture. Bitumen cohesion is the cohesive bond strength of the material and is estimated as twice the total surface energy of the material. Dry bond strength $\left(W_{B A}^{a}\right)$ is defined as given in Eq. 12 as the interfacial work of adhesion between the bitumen $(B)$ and aggregate $(A)$. A bigger value of dry bond strength suggests greater adhesion between the two materials and hence more resistance against debonding.

$$
W_{B A}^{a}=2 \sqrt{\gamma_{B}^{L W} \gamma_{A}^{L W}}+2 \sqrt{\gamma_{B}^{+} \gamma_{A}^{-}}+2 \sqrt{\gamma_{B}^{-} \gamma_{A}^{+}}
$$

Eq. 13 gives the work of debonding $\left(W_{B W A}^{a}\right)$ which is considered as the reduction in bond strength of a bitumen-aggregate system when water $(W)$ is introduced into the system or when water displaces the bitumen from the aggregate surface. A smaller value of this parameter for a given bitumen-aggregate system is indicative of a better moisture damage performance of that system.

$$
\begin{aligned}
& W_{B W A}^{a}=\left\{\left(\left(\sqrt{\gamma_{A}^{L W}}-4.67\right)^{2}\right)+\left(2 \times\left(\sqrt{\gamma_{A}^{+}}-5.05\right) \times\left(\sqrt{\gamma_{A}^{-}}-5.05\right)\right)\right\} \\
& +\left\{\left(\left(\sqrt{\gamma_{B}^{L W}}-4.67\right)^{2}\right)+\left(2 \times\left(\sqrt{\gamma_{B}^{+}}-5.05\right) \times\left(\sqrt{\gamma_{B}^{-}}-5.05\right)\right)\right\} \\
& -\left\{\left(\left(\sqrt{\gamma_{B}^{L W}}-\sqrt{\gamma_{A}^{L W}}\right)^{2}\right)+\left(2 \times\left(\sqrt{\gamma_{B}^{+}}-\sqrt{\gamma_{A}^{+}}\right) \times\left(\sqrt{\gamma_{B}^{-}}-\sqrt{\gamma_{A}^{-}}\right)\right)\right\}
\end{aligned}
$$

\subsection{Bitumen-aggregate bond energy parameters}

The ratio $\left(\mathrm{ER}_{1}\right)$ between the adhesive bond energy values in the dry condition $\left(W_{B A}^{a}\right)$ and in the presence of water $\left(W_{B W A}^{a}\right)$ can be used to predict the moisture sensitivity of asphalt mixtures. A higher value of energy ratio indicates better resistance to moisture damage for that bitumen-aggregate combination. Bhasin et al. (2006) used energy ratio $E_{1}$ to study different types of asphalt mixtures and concluded that mixtures with a ratio higher than 1.5 were more moisture resistant than the ones with ratios lower than 0.8 . 
$E R_{1}=\left|\frac{W_{B A}^{a}}{W_{B W A}^{a}}\right|$

Aggregates with higher surface roughness and greater surface area are supposed to bond better with bitumen by providing more bond area and better interlocking. In order to accommodate this effect, a second bond energy parameter (ER $\left.{ }_{1}^{*} \mathrm{SSA}\right)$ obtained by multiplying the bond energy ratio $\left(\mathrm{ER}_{1}\right)$ with specific surface area (SSA) has been proposed in addition to $\mathrm{ER}_{1}$ to predict moisture sensitivity of asphalt mixtures.

Wetting/coating of an aggregate with bitumen is not only affected by the surface properties of the two materials; the viscosity or cohesion of the bitumen itself also plays a very important role. Bitumen with lesser cohesion and greater affinity for the aggregates will have a higher wettability and will coat the aggregate surface more than bitumen having lesser wettability characteristics. However, softer bitumen having lesser cohesion may be more prone to emulsification (decrease in cohesion) in the presence of water. The effects of cohesion and wettability on moisture resistance can be accounted for by modifying the $\mathrm{ER}_{1}$ parameter by replacing the bond strength in the dry condition $\left(W_{B A}^{a}\right)$ with a wettability relationship $\left(W_{B A}^{a}-W_{B B}\right)$. This new moisture sensitivity assessment parameter $\left(\mathrm{ER}_{2}\right)$ is given by Eq. 15 . In order to accommodate the effects of aggregate micro-texture on the bitumen-aggregate bond strength in the presence of moisture, the bond parameter $\mathrm{ER}_{2}$ can be multiplied by specific surface area of the aggregates to obtain a fourth bond energy parameter $\left(\mathrm{ER}_{2} * \mathrm{SSA}\right)$.

$$
E R_{2}=\left|\frac{W_{B A}^{a}-W_{B B}}{W_{B W A}^{a}}\right|
$$

Where $\left(W_{B A}^{a}\right)$ and $\left(W_{B B}\right)$ represent bitumen-aggregate dry bond strength and bitumen cohesion respectively.

These four bitumen-aggregate bond energy parameters $\left(E R_{1}, E R_{1} \times S S A, E R_{2}\right.$ and $E R_{2} \mathrm{x} S S A$ ) were used to assess the moisture susceptibility of the asphalt mixtures. In 
all cases, higher energy ratios are associated with mixtures with better moisture resistance.

\subsection{Rolling Bottle Test}

The rolling bottle test (RBT) was conducted in accordance with EN 12697-11 (Bituminous mixtures - Test methods for hot mix asphalt Part 11 - Determination of the affinity between aggregate and bitumen). Dust-free aggregate (passing $5 \mathrm{~mm}$ and retained on $2.36 \mathrm{~mm}$ sieve) samples weighing $170 \mathrm{~g}$ were dried in an oven at $105 \pm 5^{\circ} \mathrm{C}$ overnight to constant mass and then coated with $5.7 \mathrm{~g}$ of molten bitumen. Mixing of the aggregates with bitumen was conducted at $120 \pm 5^{\circ} \mathrm{C}$. The aggregate-bitumen mixture was then cooled loose at room temperature. The loose mixture was stored at ambient temperature for 12 to 64 hours before testing. Each of the test bottles were filled to about half their volume with deionized water and about $150 \mathrm{~g}$ of the loose aggregate-mixture was placed in each bottle. The whole assembly was put in the bottle roller rotating at a speed of 60 rotations per minute for six hours.

At the end of the test, the degree of bitumen coverage of the aggregate particles were estimated by visual observation and recorded to the nearest $5 \%$. The procedure (i.e. rotation in the bottle roller and measuring of bitumen coverage) is repeated for three more cycles ( 24 hours, 48 hours, and 72 hours) with fresh water replacing the fouled water in the test bottle at the end of each cycle and the degree of bitumen coverage being measured.

\subsection{Saturation Ageing Tensile Stiffness (SATS) Test}

The saturation ageing tensile stiffness (SATS) test is the first procedure of its kind that combines the ageing and water damage mechanisms to which an asphalt pavement is subjected in service within a single laboratory test. The test has been found to successfully reproduce the loss in stiffness observed with high modulus asphalt material in the field (Collop et al. 2004a), and to distinguish between poor performing material and alternative mixtures incorporating aggregate with good durability track records, when manufactured at $4 \%$ binder content and $8 \%$ air voids (Choi et al, 2002, Airey et al. 2003, Collop et al. 2004b and Choi, 2005). It has also 
been shown that the SATS test is able to rank asphalt mixtures in terms of moisture sensitivity, in the same order as the AASHTO T283 procedure (Anon, 2000), although the relative performance of a mixture containing a moisture sensitive aggregate was significantly lower in the SATS test (Airey et al., 2006).

The standard SATS procedure involves conditioning five pre-saturated specimens simultaneously in a pressure vessel under $2.1 \mathrm{MPa}$ air pressure at a temperature of 85 ${ }^{\circ} \mathrm{C}$ for a period of 65 hours. This conditioning is followed by a cooling period of 24 hours before the air pressure is released and the vessel opened to remove the specimens for stiffness testing. This procedure is applicable for asphalt mixture specimens made with 15 pen bitumen with a modified SATS protocol being used to test asphalt mixtures with softer 50 pen and 100 pen binders (Grenfell et al., 2012).

\section{Results}

\subsection{DCA Tests}

Results of the DCA contact angle measurements for the three bitumens and three probe liquids are presented in Figure 9. From Figure 9, it can be seen that water exhibited the largest contact angle values $\left(93.0-95.1^{\circ}\right)$ with the bitumen followed by glycerol $\left(80.2-84.2^{\circ}\right)$ and then diiodomethane $\left(58.3-68.9^{\circ}\right)$. The higher the contact angle between a solid and a liquid, the lower the potential for the two to adhere to each other. In general contact angles above $70^{\circ}$ suggest hydrophobic tendencies, therefore, the results appear to support the hydrophobic nature of bitumen.

The contact angle values were used to estimate surface energy components as previously discussed. The resulting surface energy components for the three bitumens are presented in Table 2. As expected, the softer 100 pen bitumen exhibited comparatively lower total surface energy $\left(19.1 \mathrm{~mJ} / \mathrm{m}^{2}\right)$ with the results for the 50 pen and 15 pen bitumen being very similar. 


\subsection{DVS tests}

For the four aggregates, only fractions passing the $5 \mathrm{~mm}$ sieve and retained on the $2.36 \mathrm{~mm}$ sieve were tested and reported in this paper. The results were used to estimate specific surface area (SSA) and equilibrium pressure from which the surface energy parameters were calculated.

\subsubsection{Specific surface area}

Specific surface area obtained for the four aggregates are presented in Table 3 using octane as the probe vapour. Specific surface area for the various aggregates showed large differences depending on aggregate type. The differences can be attributed to the different microstructure of the aggregates. The specific surface area obtained for each aggregate was used in two different ways: 1) to determine the equilibrium spreading pressure and 2) to calculate the moisture compatibility ratios.

\subsubsection{Equilibrium spreading pressure}

The SSA values were used to calculate the equilibrium spreading pressures on the aggregate surfaces for all three probes. Octane, being non-polar in nature, is supposed to give more accurate values of surface area (because non-polar substances do not have affinity for polar substances). The obtained spreading pressures are provided in Table 4.

\subsubsection{Surface energy components}

Computed surface energy components $\left(\gamma_{S}^{L W}, \gamma_{S}^{+}, \gamma_{S}^{-}\right)$as well as the total surface energy $\left(\gamma_{S}^{T}\right)$ for the aggregates are provided in Table 5. The results show that surface energy properties vary considerably, in terms of surface energy components as well as total surface energy, amongst the different aggregates. The differences can be attributed to different elemental and mineralogical compositions of the aggregates. The test results indicate that there is not a big difference between the van der Waals 
components of the aggregates though Limestone A has a value $\left(75.2 \mathrm{~mJ} / \mathrm{m}^{2}\right)$ that is slightly higher than the SE $\left(67.8 \mathrm{~mJ} / \mathrm{m}^{2}\right)$ for Granite A.

Differences were seen when the total surface energy of the four aggregates (a measure of adhesive potential of a material) are compared. On the basis of total surface energy alone, and for the same bitumen, Granite $\mathrm{A}\left(\gamma^{\mathrm{T}}=353.5 \mathrm{~mJ} / \mathrm{m}^{2}\right)$ should theoretically form stronger adhesive bond than Limestone A $\left(\gamma^{T}=222.7 \mathrm{~mJ} / \mathrm{m}^{2}\right)$. Note that this assertion assumes a completely dry aggregate.

\subsection{Dry and wet work of adhesion}

Work of adhesion results for the various aggregate-bitumen combinations are presented in Table 6 . The results show both the influence of the different aggregates and bitumen on work of adhesion. Work of debonding values for the aggregatebitumen combinations are presented in Table 7. In addition to the work of adhesion, the greater the magnitude of work of debonding when water displaces bitumen from the aggregate-bitumen interface, the greater will be the thermodynamic potential that drives moisture damage. The results show that for a given aggregate, work of debonding increases (in magnitude) for softer bitumen compared to harder (stiffer) binders. Similarly the effect of aggregate on work of debonding increases as one moves from limestone to granite.

\subsection{Aggregate-bitumen bond energy parameters related to moisture damage}

Table 8 shows the aggregate-bitumen bond energy parameters $\left(\mathrm{ER}_{1}, \mathrm{ER}_{2}, \mathrm{ER}_{1} * \mathrm{SSA}\right.$ and $\mathrm{ER}_{2} * \mathrm{SSA}$ ) for the asphalt mixtures. These four bond energy parameters can be used to predict moisture sensitivity of asphalt mixtures using threshold values defined to separate 'good' from 'poor' moisture damage performing aggregate-bitumen combinations. The threshold limits are 0.75 for $\mathrm{ER}_{1}, 0.50$ for $\mathrm{ER}_{2}, 0.50$ for $\mathrm{ER}_{1} * \mathrm{SSA}$ and 0.35 for $\mathrm{ER}_{2} * \mathrm{SSA}$ (Bhasin, 2006; Bhasin et al., 2006).

The aggregate-bitumen combinations that are classified as 'poor' based on these threshold limits are shown in bold and underlined in Table 9. The results show that the ranking of the 'good' versus 'poor' moisture damage performing aggregate- 
bitumen combinations for $\mathrm{ER}_{1}$ and $\mathrm{ER}_{2}$ are quite similar; both parameters placing the same number of combinations in 'good' versus 'poor' categories. The results for the other two parameters, $\mathrm{ER}_{1} * \mathrm{SSA}$ and $\mathrm{ER}_{2} * \mathrm{SSA}$, are also similar but the later placed slightly more mixtures in the 'poor' category. The results suggest, for the materials considered, that $\mathrm{ER}_{1}$ and $\mathrm{ER}_{2}$ are sensitive to binder cohesion as the softer 100 pen bitumen showed lower ratios irrespective of the aggregate type.

Compared to the $\mathrm{ER}_{1}$ and $\mathrm{ER}_{2}$ parameters, the results for $\mathrm{ER}_{1} * \mathrm{SSA}$ and $\mathrm{ER}_{2} * \mathrm{SSA}$ show the significant influence of SSA on the selection of 'good' versus 'poor' moisture damage performing aggregate-bitumen combinations. Because of the apparent large influence of SSA on moisture sensitivity of asphalt mixtures shown in Table 8, the bond parameters $\mathrm{ER}_{1} * \mathrm{SSA}$ and $\mathrm{ER}_{2} * \mathrm{SSA}$ appear to be more suitable indices for determining the performance of the different aggregate-bitumen combinations with a clear distinction in terms of 'good' and 'poor' aggregates. Most of the granite-bitumen combinations were identified as 'poor' aggregates which is in agreement with past field experience with these aggregates.

\subsection{RBT tests}

In the RBT method, the degree of bitumen coverage of the coated aggregate particles was assessed after 6 hours, 24 hours, 48 hours, and 72 hours of conditioning in a bottle roller. Sample results for two aggregates (Limestone A and Granite A) coated with 50 pen bitumen are presented in Figure 10. Similar results were obtained for all the aggregate-bitumen combinations. From Figure 10, it could be seen that the percentage of bitumen coverage decreased slowly with testing time for Limestone A, while on the contrary, percentages for Granite A reduced sharply during the test period. For instance, during the first six hours, Limestone A showed only a $2 \%$ binder loss while Granite A showed about $20 \%$ loss. In addition, the percentage of binder loss for granite at 6 hours is equal to that for the limestone aggregate at 72 hours. The RBT results in Figure 10 ranking the limestone aggregate as better than the granite is in agreement with both the surface energy results presented in Table 8 and the observed field performance of these aggregates. 


\subsection{SATS tests}

SATS tests were carried out using the modified SATS protocol (Grenfell et al., 2012) on both the limestone and the granite aggregates in the form of 0/32 mm dense roadbase mixtures using the same 50 pen bitumen. Results from the SATS tests can be seen in Figure 11, which demonstrates the superior moisture resistance of the mixture made with the limestone aggregate. It can be seen that the retained stiffness for the limestone mixture specimens is in excess of 0.8 , whereas for the granite mixture, the retained stiffness ranges from 0.2 to 0.5 . It is generally accepted that if a retained stiffness of less than 0.6 is achieved that a mixture is considered moisture susceptible. This suggests the granite mixtures are more moisture sensitive than the limestone mixtures.

\section{Discussion}

As previously indicated, the key objective of this study was to determine if the moisture sensitivity assessment parameters for different bitumen-aggregate combinations obtained by using surface energy parameters of the individual materials can identify 'good' and 'poor' performing asphalt mixtures and to determine how the surface energy-based prediction compare with two standard asphalt mixture tests (RBT and SATS). Figure 12 shows a plot depicting the relationships between SATS retained stiffness and the bond energy parameter $\mathrm{ER}_{1}$ compare with the RBT percent bitumen coverage. In all cases a higher value of the parameter suggests better resistance to moisture damage. On this basis, aggregate-bitumen combinations plotting near the upper right hand side of the plot (equivalent to higher values of $E_{1}$, RBT coverage and/or SATS retained stiffness) are expected to be more moisture resistant than mixtures plotting in the lower left hand side. The results show that limestone mixtures should be expected to perform better than granite mixtures. The results also illustrate the close agreement between the three techniques for evaluating moisture sensitivity.

The 'good' performance of most of the limestone mixtures observed in this study could be attributed to several physico-chemical and mineralogical characteristics of the aggregates used. Analysis of the sorption isotherms indicated differences in 
surface energy characteristics of the aggregates. The effect of physico-chemical characteristics of the aggregates is manifested in the sensitivity of the bond energy parameters presented in Table 8.

Results of mineralogical characterisation of the aggregates determined using an MLA on samples of both the limestone and the granite aggregates are presented in Table 1. The differences in moisture sensitivity seen in the aggregates can be attributed in part to the mineralogical characteristics of the aggregates.

\section{Conclusions}

This paper presents results from the RBT and SATS tests in an attempt to better understand the underlying processes and mechanisms of moisture damage with the help of surface energy measurements on the constituent materials (bitumen and aggregates) and aggregate morphology from MLA measurements. The following conclusions were reached based on the results presented in the paper.

- $\quad$ Surface energy parameters obtained from the DCA testing suggests cohesive strength varies with bitumen grade. Surface energy of the softest bitumen tested (100 pen) was about 60\% that of the stiffer bitumens (15 pen and 50 pen).

- The adhesive bond strengths for both the dry and the wet conditions were used to compute four compatibility ratios using the surface energy parameters obtained for the bitumen and aggregates. Higher magnitudes of the ratios suggest better resistance to moisture damage. The results show that for a given aggregate, moisture resistance of stiffer binders is higher than softer binders. The results also show that for a given bitumen grade, and for the aggregates considered in this study, the limestone aggregate mixtures should exhibit higher resistance (higher ratios) to moisture damage.

- $\quad$ The four aggregate-bitumen bond energy parameters $\left(\mathrm{ER}_{1}, \mathrm{ER}_{2}, \mathrm{ER}_{1} * \mathrm{SSA}\right.$ and $\mathrm{ER}_{2} * \mathrm{SSA}$ ) can be used to predict moisture sensitivity of asphalt mixtures using threshold values $\left(0.75\right.$ for $\mathrm{ER}_{1}, 0.50$ for $\mathrm{ER}_{2}, 0.50$ for $\mathrm{ER}_{1} * \mathrm{SSA}$ and 0.35 for $\mathrm{ER}_{2} * \mathrm{SSA}$ ) defined to separate 'good' from 'poor' moisture damage performing aggregate-bitumen combinations. Most of the aggregates that were 
identified as 'poor' aggregates in this study have also been found to perform poorly in previous studies.

- Compared to the $\mathrm{ER}_{1}$ and $\mathrm{ER}_{2}$ parameters, the results for $\mathrm{ER}_{1} * \mathrm{SSA}$ and $\mathrm{ER}_{2} * \mathrm{SSA}$ showed the significant influence of SSA on the selection of 'good' versus 'poor' moisture damage performing aggregate-bitumen combinations. Because of the apparent large influence of SSA on moisture sensitivity of asphalt mixtures shown in this study, the bond parameters $\mathrm{ER}_{1} * \mathrm{SSA}$ and $\mathrm{ER}_{2} * \mathrm{SSA}$ appear to be more suitable indices for determining the performance of the different aggregate-bitumen combinations with a clear distinction in terms of 'good' and 'poor' aggregates.

- $\quad$ Results from the RBT showed that the percentage of bitumen coverage (a measure of adhesiveness) varies depending on aggregate type. About $90 \%$ of the limestone aggregate remained coated with bitumen at the end of the rolling bottle test compared with only $20 \%$ for the granite aggregate. This suggests that in the presence of moisture, limestone aggregate maintains a better adhesive bond with bitumen than granite aggregate which agrees with the surface energy ranking of the mixtures.

- Moisture damage factors (moisture factors) obtained from the SATS tests for limestone aggregate asphalt mixtures were comparatively higher than that for granite mixtures. Higher moisture factors indicate better moisture resistance. Thus the SATS test results appear to be in agreement with the RBT as well as the surface energy parameters.

- $\quad$ Mineralogical testing of the aggregates, using MLA, showed that Limestone A is composed predominantly (97\%) of calcite with trace amounts of quartz $(0.5 \%)$ while the dominant mineral phases in Granite A consisted of quartz (33\%), albite (28\%), and feldspar (17\%). Therefore, the differences in moisture sensitivity of the mixtures observed in this study for the different aggregates can be attributed in part to aggregate mineralogy.

- It is concluded that moisture resistance of asphalt mixtures are influenced by the mineralogical composition of the aggregates as well as the adhesive bond between the aggregate and bitumen in the presence of moisture. Both the RBT and SATS are useful in evaluating moisture damage in asphalt mixtures as the 
ranking obtained in these empirical tests are similar to surface energy and mineralogical characteristics of the asphalt mixtures.

- The research undertaken in the paper has contributed towards a better understanding of the moisture susceptibility of asphalt mixtures. The surface energy testing protocols and adhesive bond strength calculations can be used to compliment available asphalt mixture design methods by identifying compatible bitumen-aggregate combinations. Surface energy properties of the materials combined with the parameters obtained by conventional moisture sensitivity assessment techniques can also contribute towards the development of a material screening protocol for determining the best combinations of bitumen and aggregates for the local road material providing better bitumenaggregate adhesion and less susceptibility to moisture damage/stripping.

\section{References}

Airey, G.D., Masad, E.A., Bhasin, A., Caro, S. and Little, D.N. (2007) Asphalt Mixture Moisture Damage Assessment Combined with Surface Energy Characterization. Proceedings of the International Conference on Advanced Characterisation of Pavement and Soil Engineering Materials, Vol. 1, 739748, Athens.

Airey, G.D., and Choi, Y.K., (2006) State of the Art Report on Moisture Sensitivity Test Methods for Bituminous Pavement Materials. Road Materials and Pavement Design. Vol. 3, No. 4, 355-372.

Airey, G.D., Choi, Y., Collop, A.C., Moore, A.J.V. and Elliott, R.C., (2006) Combined laboratory ageing / moisture sensitivity assessment of high modulus base asphalt mixtures. Proceedings of the Association of Asphalt Paving Technologists, Vol. 74, 307-346.

Airey, G.D., Choi, Y., Collop, A.C. and Elliott, R.C., (2003) Development of an accelerated durability assessment procedure for high modulus base (HMB) materials. 6th International RILEM Symposium on Performance Testing and Evaluation of Bituminous Materials, PTEBM'03, Zurich, Switzerland.

Annual Local Authority Road Maintenance (Alarm) Survey. (2006) Asphalt Industry Alliance, www.asphaltindustryalliance.com/alarm.asp. 
Anon, (2000) Resistance of compacted bituminous mixtures to moisture induced damage. AASHTO T283-99, American Association of State Highways and Transportation Officials, USA.

Bhasin, A. (2006) Development of Methods to Quantify Bitumen-Aggregate Adhesion and Loss of Adhesion due to Water: PhD dissertation, Texas A\&M University, USA.

Bhasin, A., Masad, E., Little, D., and Lytton, R., (2006) Limits on Adhesive Bond Energy for Improved Resistance of Hot-Mix Asphalt to Moisture Damage. Transportation research record: Journal of the Transportation Research Board, No. 1970, Washington D.C., 3-13.

Birgisson, B., Roque R., Tia, M. and Masad, E. (2005) Development and Evaluation of Test methods to Evaluate Water Damage and Effectiveness of Antistripping Agents. Project Number 4910-4504-722-12 from Florida Department of Transportation: Florida.

Cheng, D. (2002) Surface Free Energy of Asphalt Aggregate System and Performance Analysis of Asphalt Concrete based on Surface Free Energy: PhD dissertation, Texas A\&M University, USA.

Cheng, D., Little, D.N., Lytton, R.L. and Holste, J.C. (2002a). Surface Energy Measurement of Asphalt and Its Application to Predicting Fatigue and Healing in Asphalt Mixtures. Transportation Research Record: Journal of the Transportation Research Board, No. 1810, TRB, National Research Council, Washington, D.C., 44-53.

Cheng, D., Little, D.N., Lytton, R.L., and Holste, J.C., (2002b) Moisture Damage Evaluation of Asphalt Mixtures by Considering both Moisture Diffusion and Repeated-Load Conditions. Transportation Research Record: Journal of the Transportation Research Board. TRR 1832, 42-49.

Choi, Y.K., Collop, A.C., Airey, G.D., Elliott, R.C., Williams, J. and Heslop, M.W., (2002) Assessment of the durability of high modulus base (HMB) materials. 6th International Conference on the Bearing Capacity of Roads, Railways and Airfields, Lisbon, Portugal.

Choi, Y.C., (2005) Development of the saturation Ageing Tensile Stiffness (SATS) Test for High Modulus Base Materials. PhD Thesis, School of Civil Engineering, University of Nottingham, UK. 
Collop, A.C., Choi, Y.K., Airey, G.D. and Elliott, R.C., (2004a) Development of the saturation ageing tensile stiffness (SATS) test. Proceedings of the ICE Transport, 157, 163-171.

Collop, A.C., Choi, Y.K. and Airey, G.D., (2004b) Development of a combined ageing / moisture sensitivity laboratory test. Euroasphalt and Eurobitume Congress, Vienna, Austria.

Emery, J. and Seddik, H. (1997) Moisture-damage of Asphalt Pavements and Antistripping Additives: Causes, Identification, Testing and Mitigation. Transportation Association of Canada, Ottawa, Canada.

Erbil, H, Y., (2006) Surface Chemistry of Solid and Liquid Interfaces, Blackwell Publishing Ltd.

Fowkes, F.M. (1962) Determination of Interfacial Tensions, Contact Angles, and Dispersion Forces in Surfaces by Assuming Additivity of Intermolecular Interactions in Surfaces, Journal of Physical Chemistry, Vol. 66, 382-382.

Good, R.J. and C.J. van Oss. (1991) The Modern Theory of Contact Angles and the Hydrogen Bond Components of Surface Energies, Modern Approach to Wettability: Theory and Application. Plenum Press, New York.

Good, R.J. (1992) Contact Angle, Wetting, and Adhesion: A Critical Review, Journal of Adhesion Science and Technology, Vol. 6, 1269-1302.

Grenfell, J., Ahmad, N. Airey, G., Collop, A. and Elliott, R. (2012) Optimising the moisture durability SATS conditioning parameters for universal asphalt mixture application, International Journal of Pavement Engineering. Vol. 13, No. 5, 433-450.

Horgnies, M., Darque-Ceretti, E., Fezai, H. and Felder, E. (2011) Influence of the interfacial composition on the adhesion between aggregates and bitumen: Investigations by EDX, XPS and peel tests, International Journal of Adhesion and Adhesives. Vol. 31, Issue 5, 238-247.

Kandhal, P.S. (1994) Field and Laboratory Evaluation of Stripping in Asphalt Pavements: State of the art. Transportation Research Record: Journal of the Transportation Research Board. TRR 1454, TRB, Washington, D.C., 36-47.

Kim, Y. R, (2009) Modelling of Asphalt Concrete, 1st ed. ASCE press USA: McGraw-Hill Construction. 
Manual Series No. 24 (MS-24), (2007) Moisture Sensitivity: Best Practices to Minimize Moisture Sensitivity in Asphalt Mixtures, Asphalt Institute, USA.

Maugis, D. (1999) Contact, Adhesion and Rupture of Elastic Solids. Springer, New York, 3-12.

Miller, J.S. and Bellinger, W.Y. (2003) Distress Identification Manual for the LongTerm Pavement Performance Program. Publication FHWA-RD-03-031. FHWA, Office of Infrastructure Research and Development, McLean, Virginia.

Shaw, D. J., (1991) Introduction to Colloid and Surface Chemistry, 4th ed. Oxford. Butterworth-Heinemann.

Sing, K. S. W., (1969) Utilisation of Adsorption Data in the BET Region. Proceedings; International Symposium on Surface area Determination, Bristol, UK.

Solaimanian, M., J. Harvey, M. Tahmoressi, and V. Tandon. (2003) Test Methods to Predict Moisture Sensitivity of Hot Mix Asphalt Pavements. Proceedings National Seminar on Moisture Sensitivity of Asphalt Pavements, San Diego, California.

Terrel R.L. and Al-Swailmi S. (1994) Water Sensitivity of Asphalt-Aggregate Mixes: Test Selection. SHRP-A-403, Strategic Highway Research Program, National Research Council, Washington, D.C. 
Table 1. Mineral composition of aggregates obtained using MLA.

\begin{tabular}{|l|c|c|}
\hline \multirow{2}{*}{ Mineral name } & \multicolumn{2}{|c|}{} \\
\cline { 2 - 3 } & Granite A & Granite B \\
\hline Quartz & 33.17 & 15.86 \\
\hline Albite & 28.30 & 32.73 \\
\hline K-feldspar & 16.93 & 9.64 \\
\hline Chlorite & 11.90 & 13.52 \\
\hline Muscovite & 4.58 & 3.43 \\
\hline Other & 1.19 & 1.91 \\
\hline Epidote & 1.06 & 1.37 \\
\hline Biotite & 1.00 & 0.34 \\
\hline Anorthite & 0.82 & 18.54 \\
\hline Calcite & 0.78 & 0.08 \\
\hline Hornblende & 0.27 & 2.57 \\
\hline & Limestone A & Limestone B \\
\hline Calcite & 96.98 & 98.94 \\
\hline Dolomite & 1.30 & 0.00 \\
\hline Clay & 0.93 & 0.37 \\
\hline Quartz & 0.49 & 0.55 \\
\hline Other & 0.30 & 0.13 \\
\hline K-feldspar &
\end{tabular}

K-feldspar = potassium-dominant feldspar

Table 2. Surface energy components of bitumen

\begin{tabular}{|c|c|c|c|c|c|}
\hline \multirow{2}{*}{ Bitumen } & \multicolumn{5}{|c|}{ Surface Energy Components $\left(\mathrm{mJ} / \mathrm{m}^{2}\right)$} \\
\cline { 2 - 6 } & $\gamma^{\mathrm{LW}}$ & $\gamma^{+}$ & $\gamma^{-}$ & $\gamma^{\mathrm{AB}}$ & $\gamma^{\mathrm{T}}$ \\
\hline 15pen & 31.1 & 0.01 & 3.37 & 0.37 & 31.4 \\
\hline 50pen & 30.6 & 0.00 & 2.40 & 0.00 & 30.6 \\
\hline 100pen & 19.1 & 0.00 & 0.78 & 0.00 & 19.1 \\
\hline
\end{tabular}

Table 3. Specific surface area $\left(\mathrm{m}^{2} / \mathrm{g}\right)$ of aggregates. SSA was obtained using octane probe liquids.

\begin{tabular}{|l|r|}
\hline Aggregate & SSA $\left(\mathrm{m}^{2} / \mathrm{g}\right)$ \\
\hline Limestone A & 0.79 \\
\hline Limestone B & 0.17 \\
\hline Granite A & 0.38 \\
\hline Granite B & 0.44 \\
\hline
\end{tabular}

Table 4. Equilibrium spreading pressure $\left(\mathrm{mJ} / \mathrm{m}^{2}\right)$ of aggregates

\begin{tabular}{|l|r|r|r|}
\hline \multirow{2}{*}{ Aggregate } & \multicolumn{3}{|c|}{ Probe liquid } \\
\cline { 2 - 4 } & Octane & Ethyl Acetate & Chloroform \\
\hline Limestone A & 37.5 & 128.5 & 63.6 \\
\hline Limestone B & 32.5 & 46.6 & 39.2 \\
\hline Granite A & 33.6 & 68.5 & 56.7 \\
\hline Granite B & 33.4 & 145.0 & 74.8 \\
\hline
\end{tabular}


Table 5. Surface Energy Characteristics of Aggregates

\begin{tabular}{|l|c|c|c|c|}
\hline \multirow{2}{*}{ Aggregate } & \multicolumn{2}{|l|}{$\begin{array}{l}\text { Surface energy components } \\
\left(\mathrm{mJ} / \mathrm{m}^{2}\right)\end{array}$} & $\begin{array}{l}\text { Total surface } \\
\text { energy }\left(\mathrm{mJ} / \mathrm{m}^{2}\right)\end{array}$ \\
\cline { 2 - 5 } & $\gamma^{\mathrm{LW}}$ & $\gamma^{+}$ & $\gamma^{-}$ & $\gamma^{\mathrm{T}}$ \\
\hline Limestone A & 75.2 & 109.0 & 49.9 & 222.7 \\
\hline Limestone B & 66.1 & 2.9 & 5.0 & 73.8 \\
\hline Granite A & 67.8 & 164.0 & 123.0 & 352.5 \\
\hline Granite B & 68.1 & 16.5 & 41.2 & 120.2 \\
\hline
\end{tabular}

Table 6. Work of adhesion $\left(\mathrm{mJ} / \mathrm{m}^{2}\right)$ between bitumen and aggregates

\begin{tabular}{|l|r|r|r|r|}
\hline Bitumen & Limestone A & Limestone B & Granite A & Granite B \\
\hline 15 pen & 136 & 97 & 141 & 141 \\
\hline 50 pen & 128 & 95 & 131 & 133 \\
\hline 100 pen & 94 & 74 & 95 & 98 \\
\hline
\end{tabular}

Table 7. Work of debonding $\left(\mathrm{mJ} / \mathrm{m}^{2}\right)$ in the presence of water

\begin{tabular}{|l|r|r|r|r|}
\hline Bitumen & Limestone A & Limestone B & Granite A & Granite B \\
\hline 15 pen & -47 & 56 & -103 & -42 \\
\hline 50 pen & -51 & 58 & -109 & -46 \\
\hline 100 pen & -68 & 54 & -127 & -64 \\
\hline
\end{tabular}

Table 8. Bond energy parameters (compatibility ratios) for aggregate-bitumen combinations. The aggregate-bitumen combinations that are classified as 'poor' are shown in bold and underlined.

\begin{tabular}{|c|c|c|c|c|}
\hline \multicolumn{5}{|c|}{$\mathrm{ER}_{1}$} \\
\hline Bitumen & Limestone A & Limestone B & Granite A & Granite B \\
\hline 15 pen & 2.89 & 1.75 & 1.37 & 3.41 \\
\hline 50 pen & 2.52 & 1.64 & 1.20 & 2.93 \\
\hline 100 pen & 1.39 & 1.36 & 0.70 & 1.54 \\
\hline \multicolumn{5}{|c|}{$\mathrm{ER}_{2}$} \\
\hline 15 pen & 1.56 & 0.61 & 0.76 & 1.86 \\
\hline 50 pen & 1.31 & 0.58 & 0.64 & 1.56 \\
\hline 100 pen & 0.82 & 0.66 & 0.44 & 0.94 \\
\hline \multicolumn{5}{|c|}{$\mathrm{ER}_{1} * \mathrm{SSA}$} \\
\hline 15 pen & 0.49 & 1.38 & 0.61 & 0.36 \\
\hline 50 pen & $\underline{0.43}$ & 1.29 & 0.53 & $\underline{0.31}$ \\
\hline 100 pen & $\underline{0.24}$ & 1.07 & $\underline{0.33}$ & $\underline{0.16}$ \\
\hline \multicolumn{5}{|c|}{$\mathrm{ER}_{2} * \mathrm{SSA}$} \\
\hline 15 pen & $\underline{0.27}$ & 0.48 & $\underline{0.34}$ & $\underline{0.20}$ \\
\hline 50 pen & $\underline{0.22}$ & 0.46 & $\underline{0.28}$ & $\underline{0.16}$ \\
\hline 100 pen & 0.14 & 0.52 & 0.19 & $\underline{0.10}$ \\
\hline
\end{tabular}




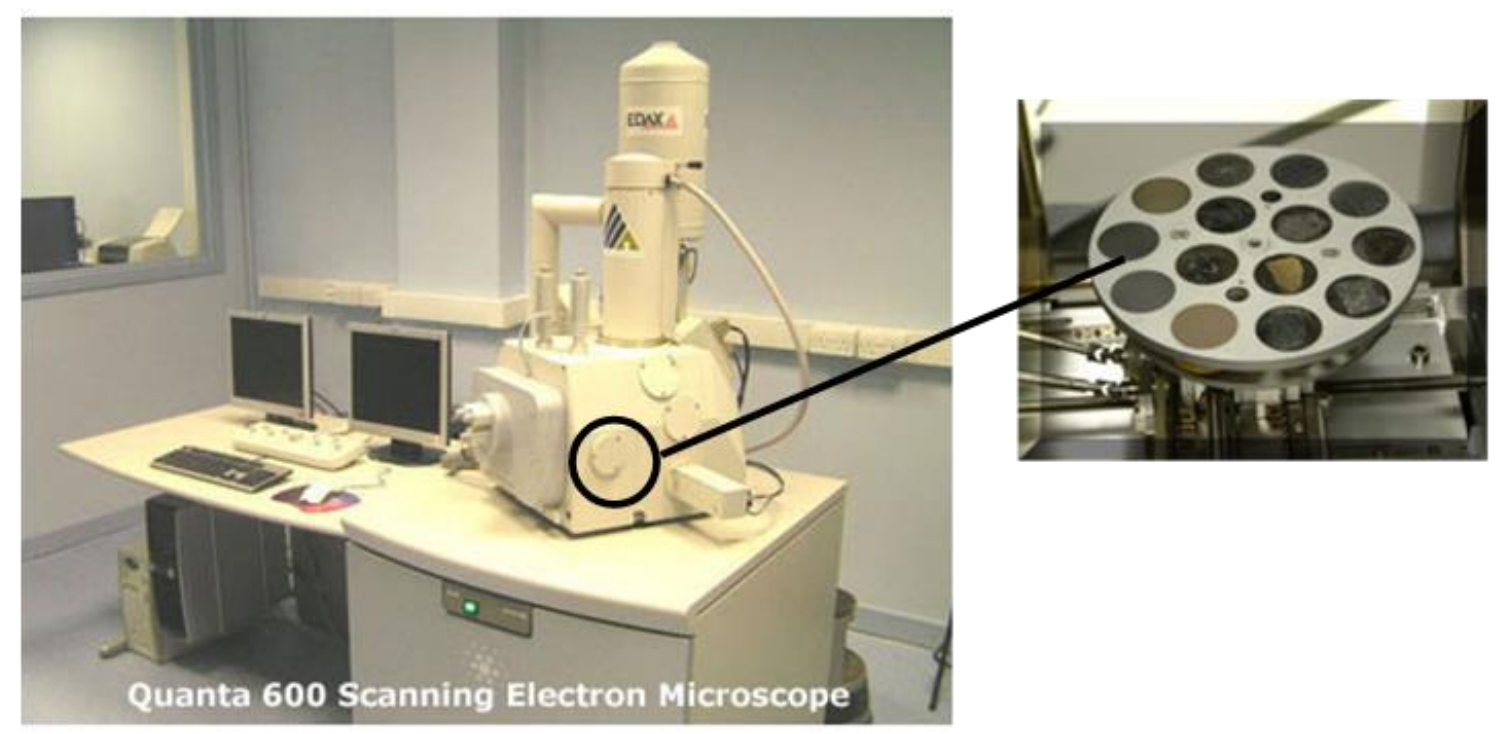

Figure 1. FEI Quanta 600 Scanning Electron Microscope (SEM) with Mineralogical Liberation Analyser (MLA). 


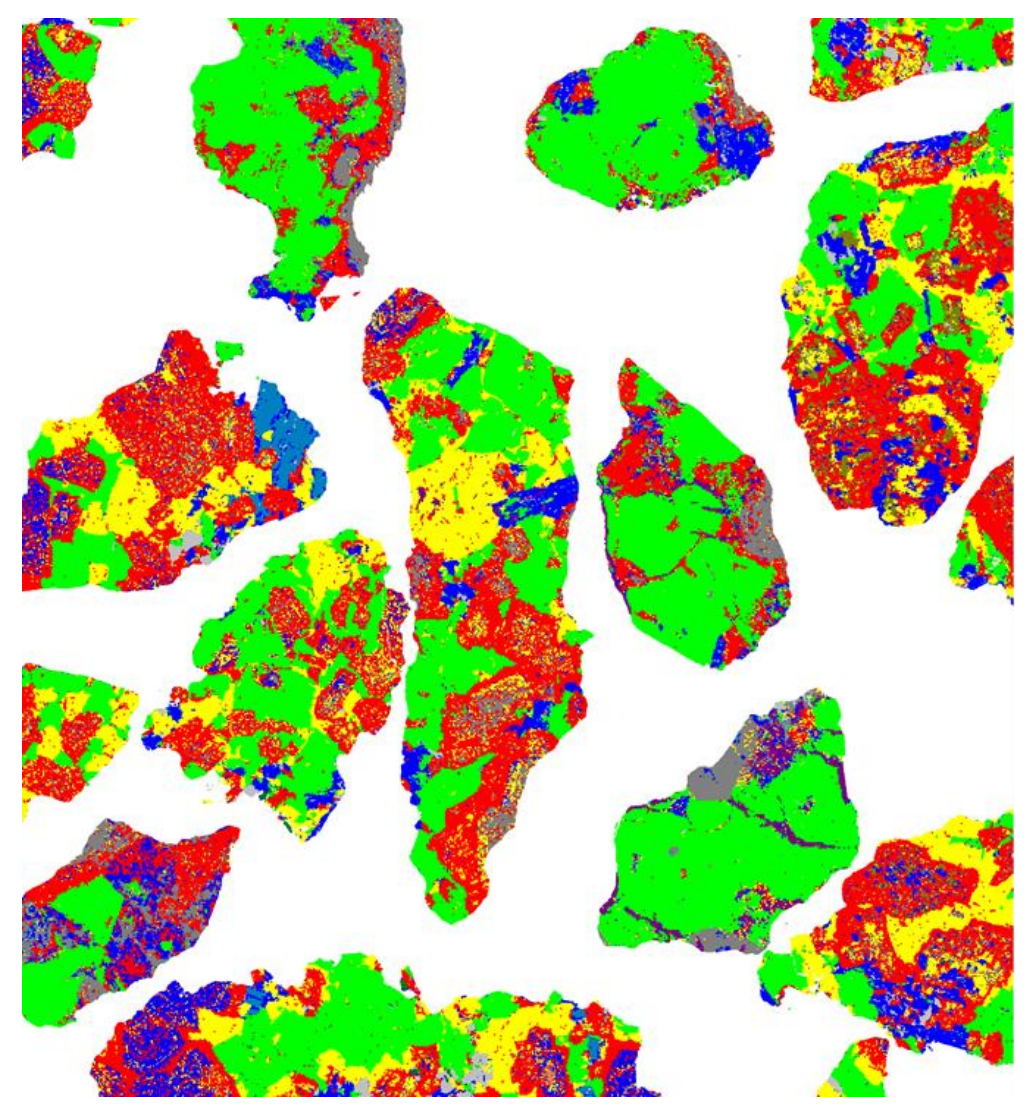

\begin{tabular}{|lr|}
\hline Quartz & 33.17 \\
\hline Albite & 28.30 \\
\hline$\square$ K_feldspar & 16.93 \\
\hline Chlorite & 11.90 \\
\hline$\square$ Muscovite & 4.58 \\
$\square$ Other & 1.19 \\
\hline$\square$ Epidote & 1.06 \\
\hline Biotite & 1.00 \\
$\square$ Anorthite & 0.82 \\
$\square$ Calcite & 0.78 \\
$\square$ Hornblende & 0.27
\end{tabular}

Figure 2. MLA analysis of Granite A aggregate.

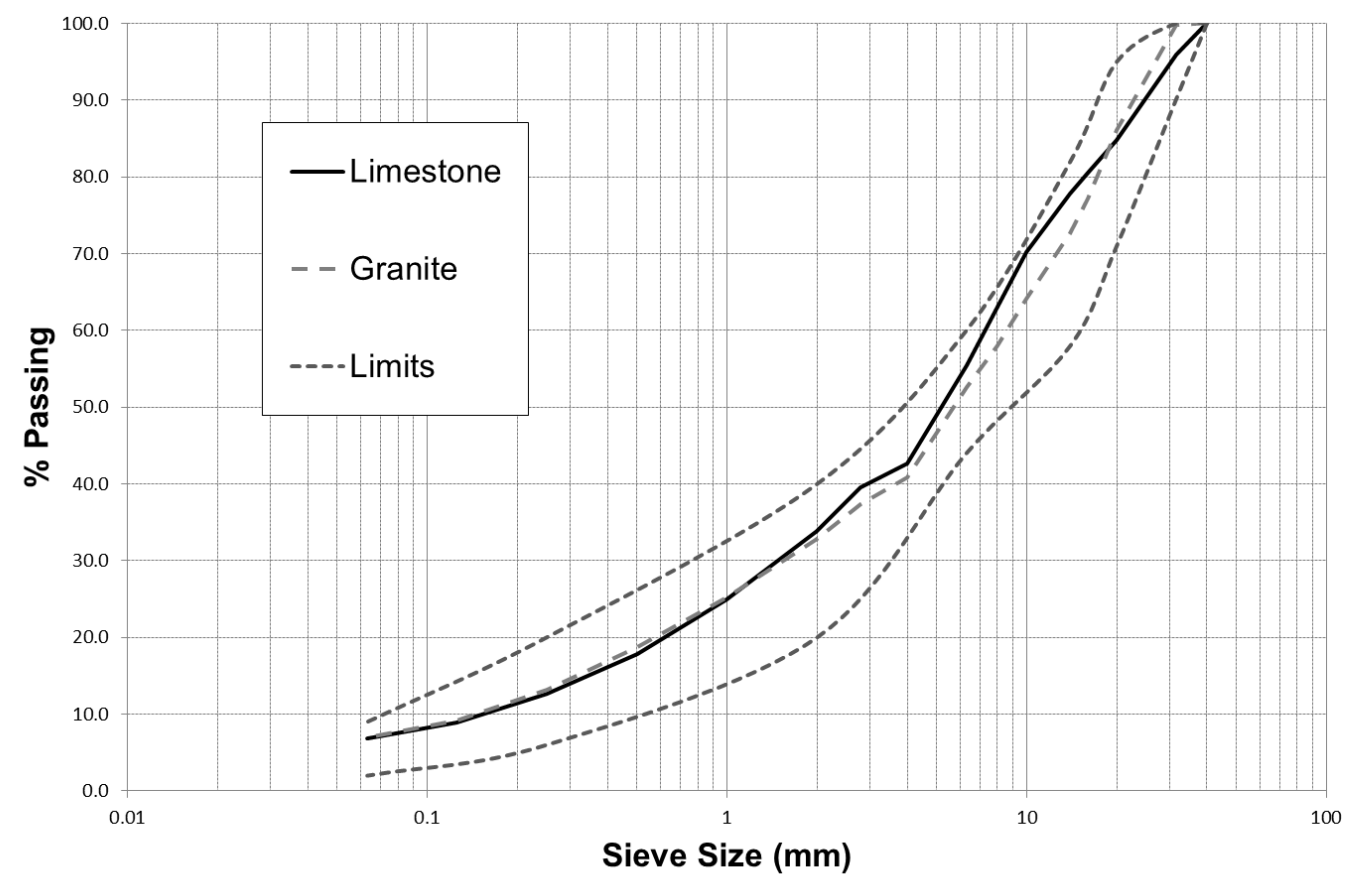

Figure 3. Gradation curves for aggregates Limestone A and Granite A for a 28mm DBM asphalt mixture. 


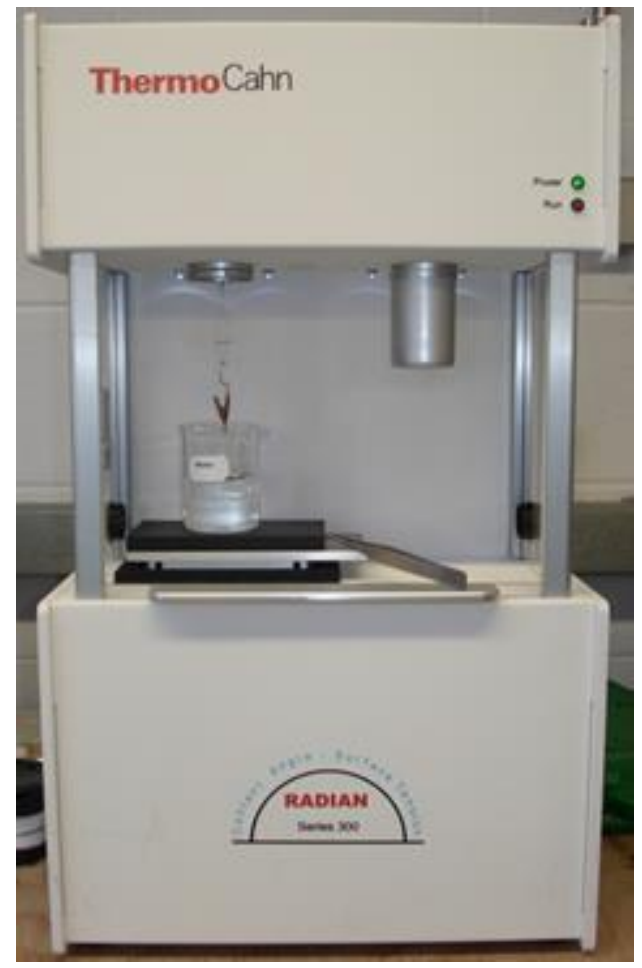

Figure 4. Dynamic contact angle analyser test set-up. A bitumen-coated glass slide hangs (via crocodile clip) from a micro-balance. A movable stage positioned directly below the bitumen-coated slide supports the probe liquid in a glass beaker. 


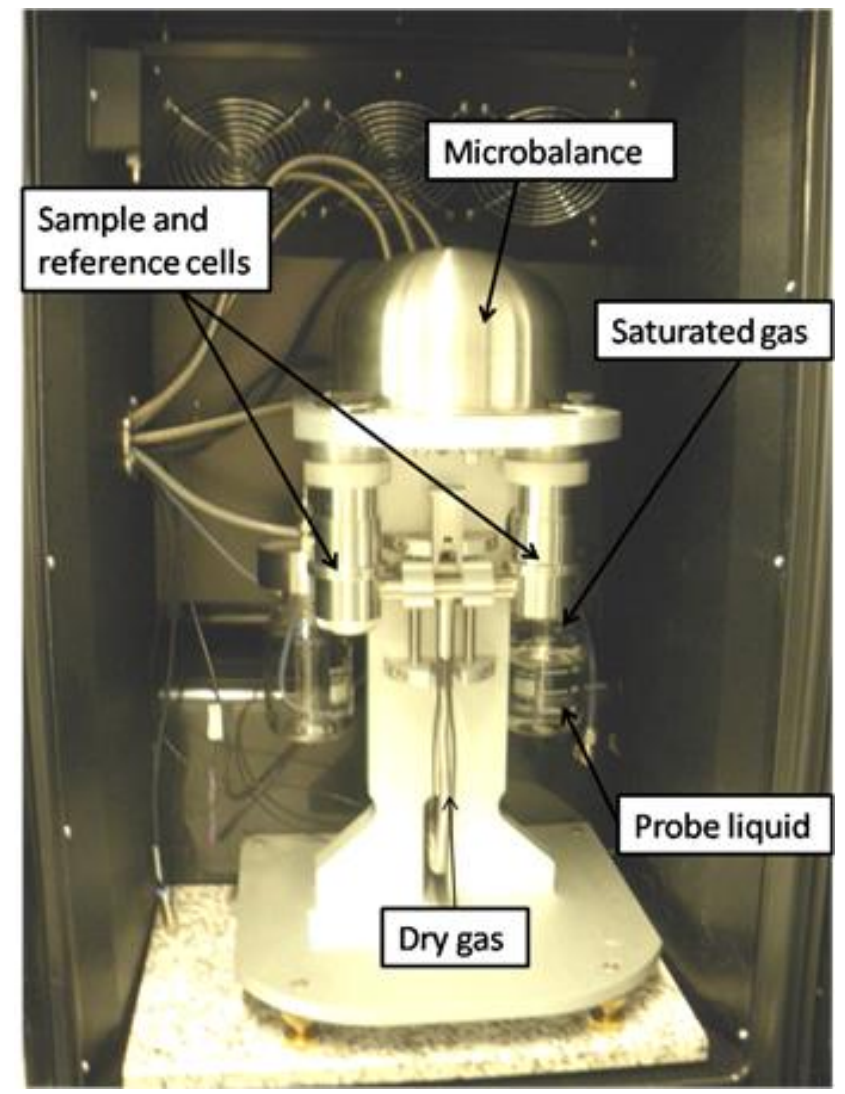

Figure 5. Dynamic vapour sorption device (DVS Advantage 2) for determining sorption isotherms of aggregates exposed to various probe liquids. An ultra-sensitive microbalance continuously measures weight changes of aggregate resulting from vapour adsorption. 


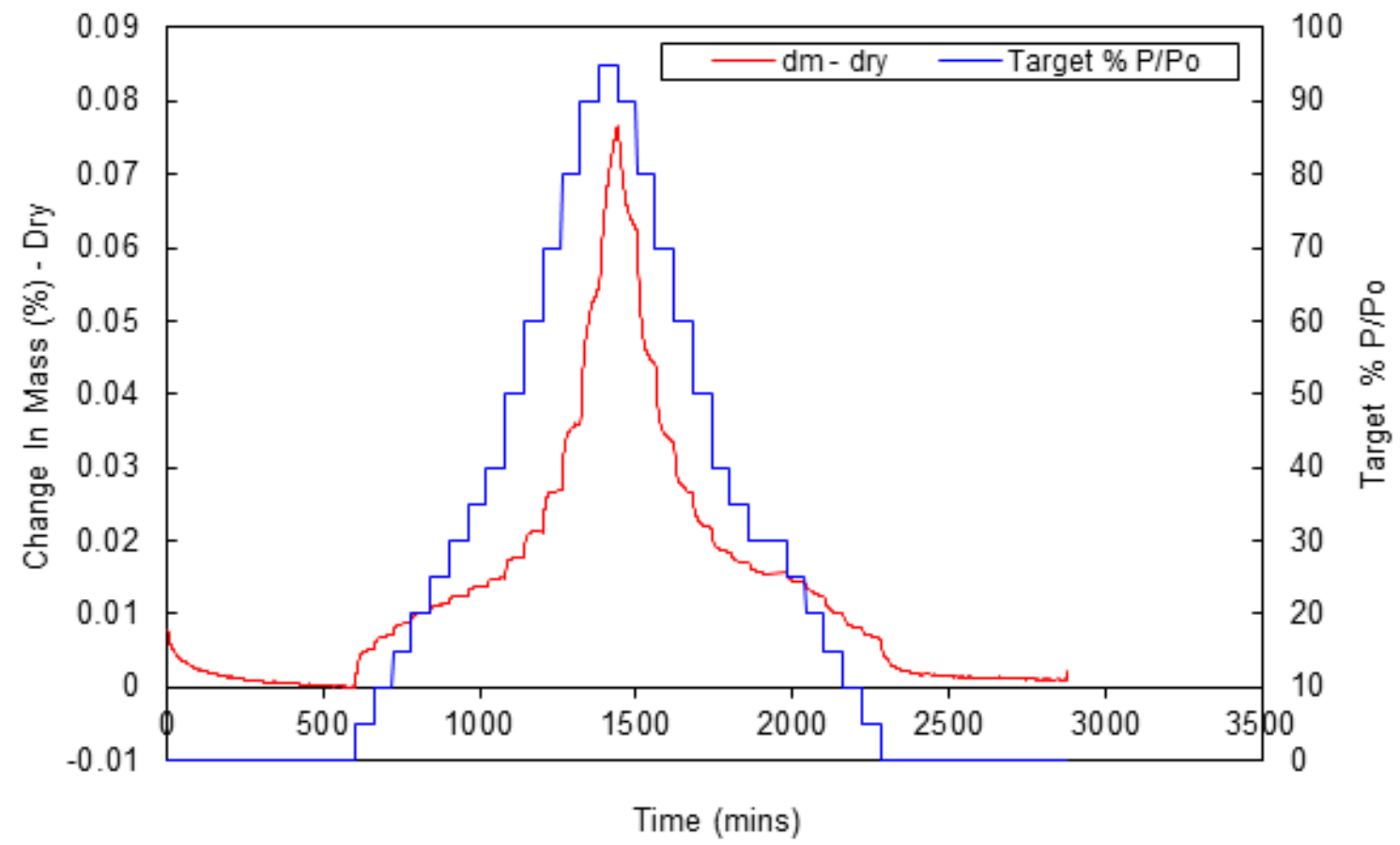

Figure 6. Sample Partial Pressure and Aggregate Change in Mass. Only the adsorption cycle was used in the computation of surface energy for this study. 


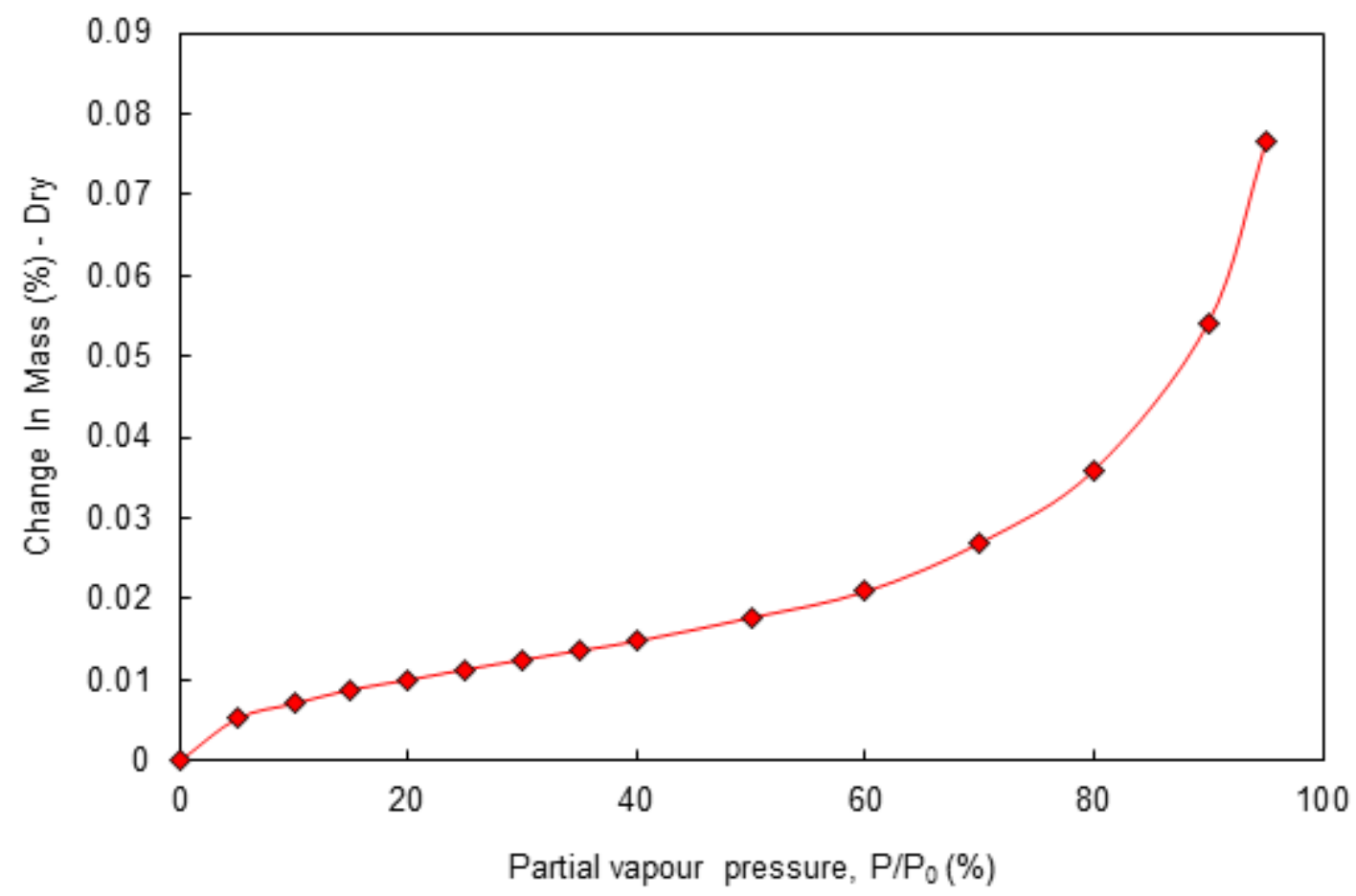

Figure 7. Typical sorption isotherm obtained for Limestone A aggregate using octane vapour as probe for partial vapour pressures (concentration) ranging from 0 to $95 \%$ with 5-10\% increments (14 steps). The isotherms

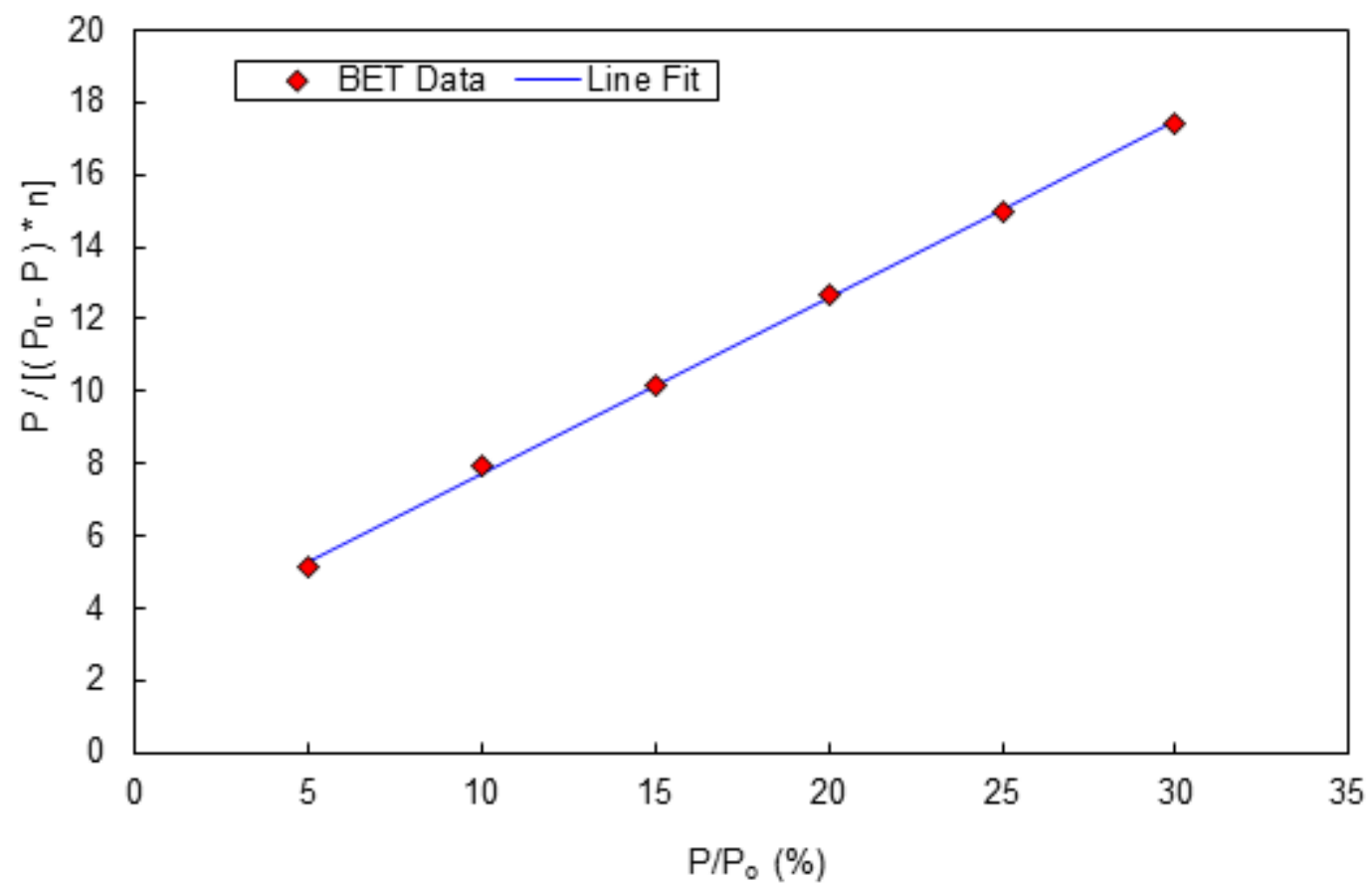

Figure 8. BET model was used to fit the sorption isotherms up to $35 \%$ partial vapour pressure. The slope and intercept of the BET plots were used to estimate the parameters $n_{m}$ and $c$ that used to calculate surface area of the aggregate. 


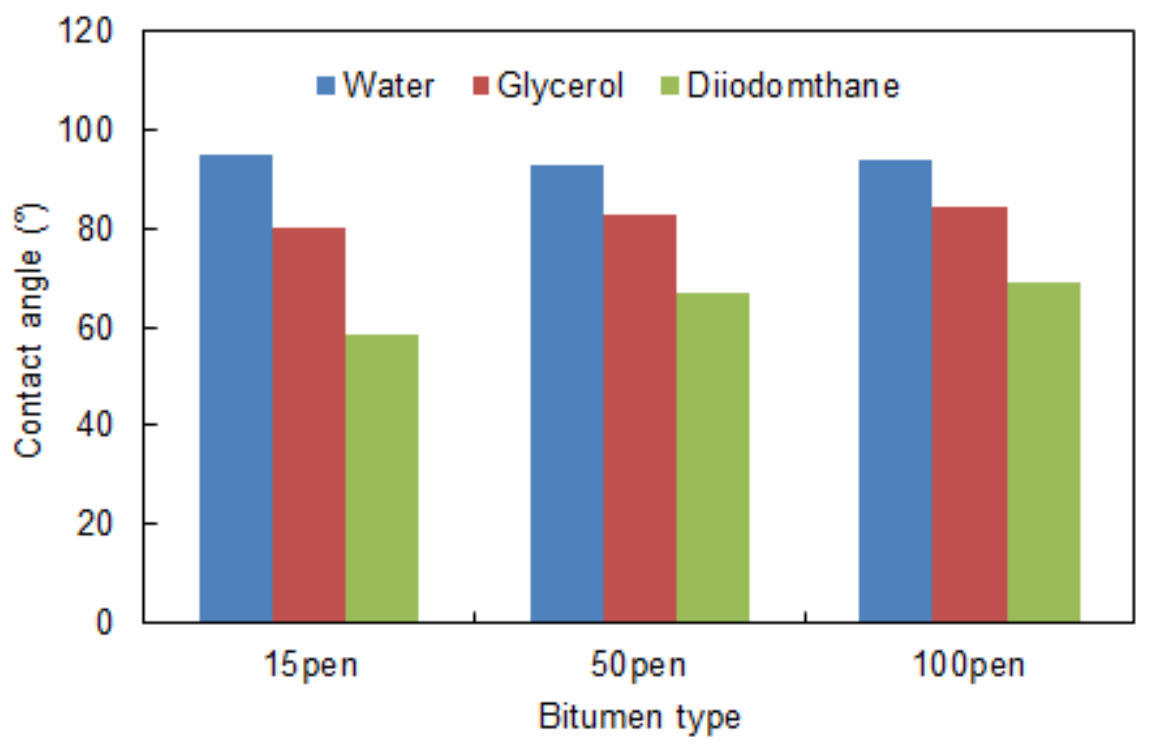

Figure 9. Contact angle of probe liquids obtained from the DCA test. The higher the contact angle between a solid and a liquid, the lower the potential for the two to adhere to each other. 


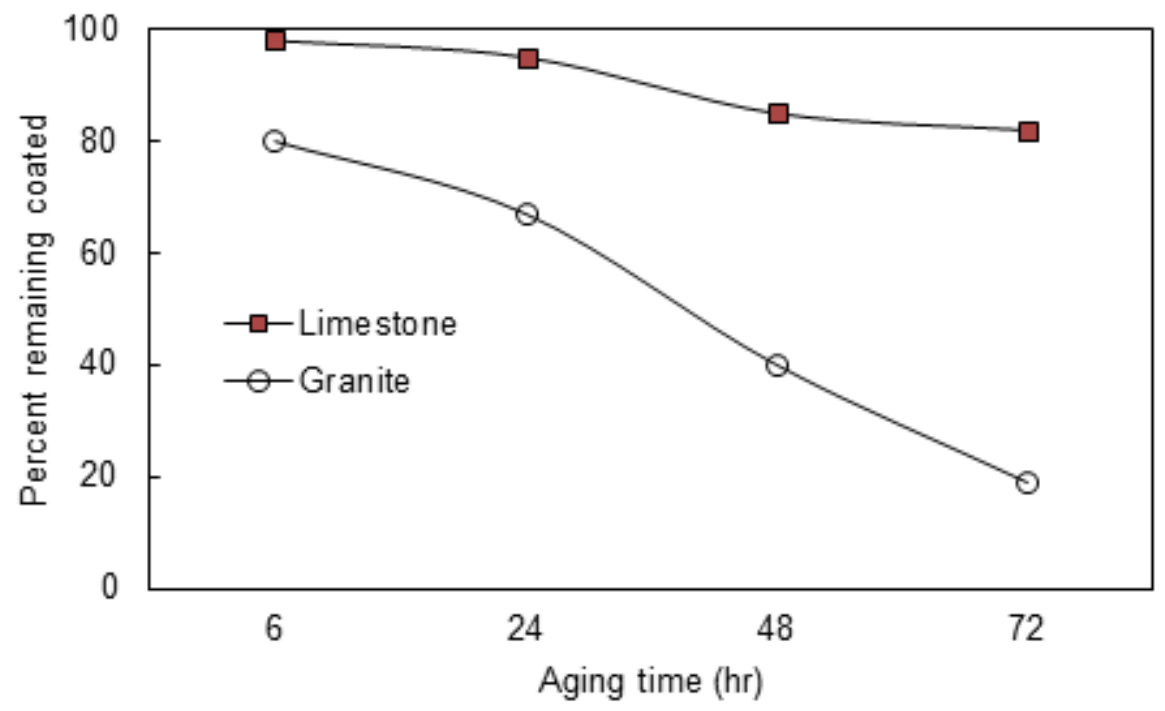

Figure 10. A plot of the percentage of aggregates that remain coated with bitumen as a function of conditioning time during the rolling bottle test. The results show Limestone A is more resistant (higher percent remaining coated) than Granite A for the mixtures considered. 


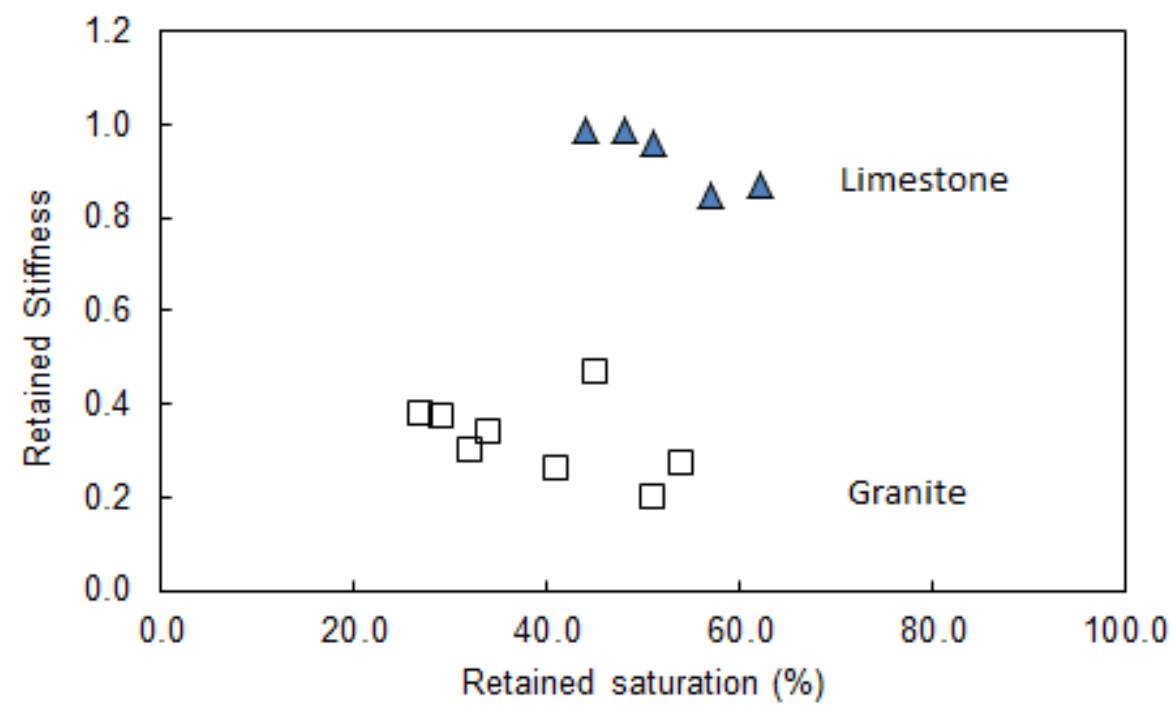

Figure 11. Comparison of SATS retained stiffness with retained saturation for 50 pen mixtures. SATS appears to rank limestone better (higher retain stiffness at a given saturation level) than granite in terms of moisture resistance. 


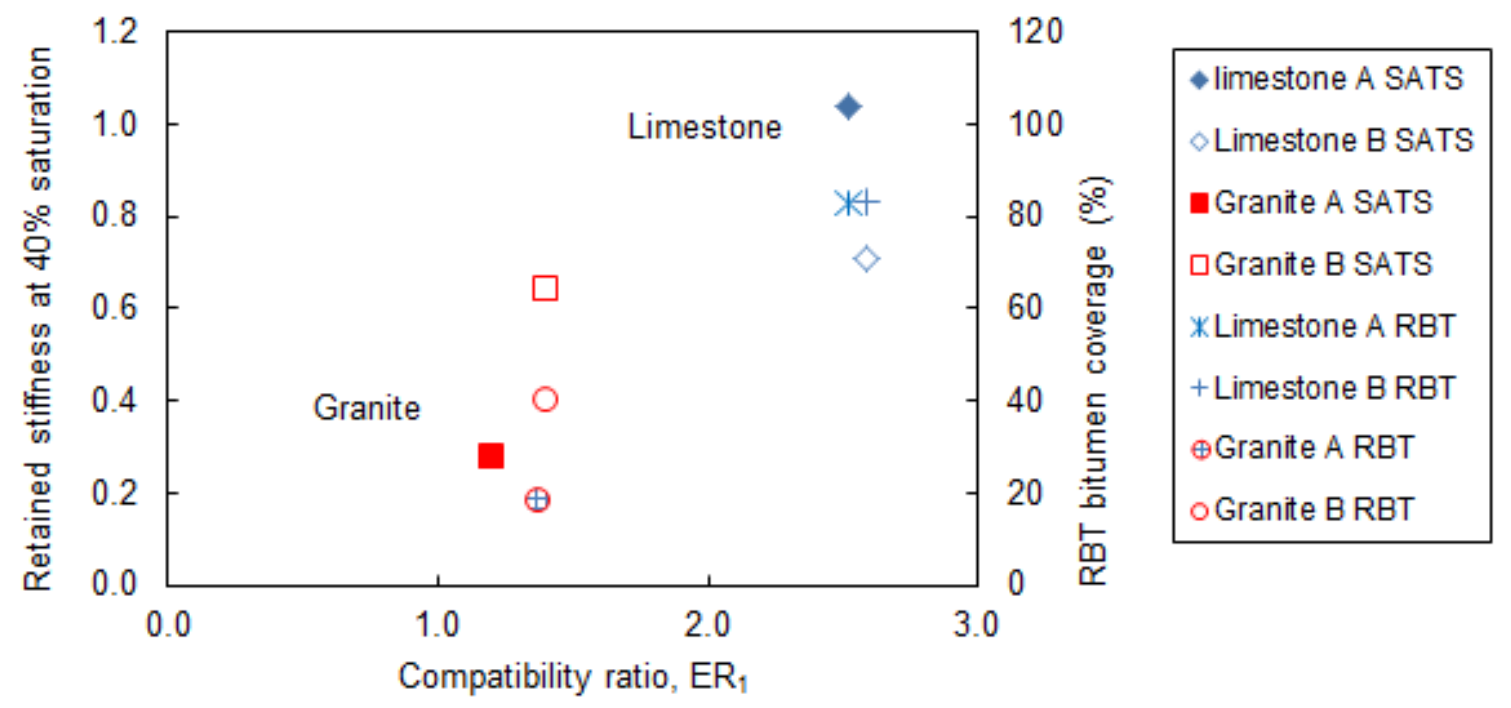

Figure 12. Plots of SATS retained stiffness and bitumen coverage during RBT as a function of bond energy ratio, $\mathrm{ER}_{1}$, for 50 pen bitumen showing the influence of aggregate type on moisture sensitivity. Both SATS and RBT ranked limestone mixtures higher (higher retained stiffness and higher bitumen coverage) than granite mixtures which is in agreement with compatibility ratio obtained from surface energy measurements. 